\title{
ANÁLISIS JURISPRUDENCIAL DE LA CARACTERIZACIÓN DE LA FAMILIA DE CRIANZA
}

Jurisprudential analysis of the characterization of the foster family.

Cesar Andrés Tirado Pertuz ${ }^{1}$

Recibido: 01 de abril 2020 - Aceptado: 14 de junio de 2020

\begin{abstract}
“La protección constitucional de la familia también se proyecta a las conformadas por padres e hijos de crianza, esto es, las que surgen no por lazos de consanguinidad o vínculos jurídicos, sino por relaciones de afecto, respeto, solidaridad, comprensión y protección". (Corte Constitucional, 2013).
\end{abstract}

\section{RESUMEN}

El reconocimiento de la familia de crianza, como una expresión de la diversidad establecida en la Constitución Política de Colombia de 1991, ha sido hasta ahora una labor, lenta y exclusiva, de la jurisprudencia nacional. No fue sino hasta septiembre del 2019 cuando se presentó un proyecto de ley que procura regular este importante tópico. En este artículo de revisión se intenta destacar las características que definen los rasgos de la familia de crianza, a partir de la interpretación de la jurisprudencia nacional y del proyecto de ley que se encuentra radicado en el Congreso de la República.

Palabras clave: Familia de crianza; hijos de crianza; filiación; vínculos paterno - filiales; patria potestad; jurisprudencia y necesidad de la prueba.

\begin{abstract}
The recognition of the substitute family, as an expression of the diversity stated on the 1991 Political Constitution of Colombia, has until now been a slow and exclusive mission of national jurisprudence. It was not until September 2019 when a bill was presented that seeks to regulate this important topic. This review article attempts to highlight the characteristics that define the characteristics of the substitute family, based on the interpretation of national jurisprudence and the law project that was introduced to the Congress of the Republic.
\end{abstract}

Keywords: Substitute family; children within a substitute family; filiation; parental - filial links; parental authority; jurisprudence and need for evidence.

\footnotetext{
1 Abogado de la Universidad de Cartagena. Especialista en Derecho de Familia, Universidad Libre de Colombia - Sede Barranquilla. Especialista en Derecho Comercial, Universidad Externado de Colombia. Abogado Asesor Tribunal Superior Sala Civil Familia de Cartagena (Colombia). Docente en las cátedras de Derecho de Familia, Derecho Civil Personas, Sucesiones y Procedimiento Mercantil en la Fundación Universitaria Antonio de Arévalo (UNITECNAR). Orcid: http://orcid.org/0000-0002-8784-3347. E-mail: cesar.tirado@ hotmail.com
} 
César Andrés Tirado Pertuz

\section{INTRODUCCIÓN}

Los artículos $5^{\circ}$ y 42 de la Constitución Política de 1991 establecen a la familia como institución básica de la sociedad, como núcleo fundamental de la sociedad; estas frases son en sí mismas un principio del estado social y democrático de Derecho en Colombia, lo que a su vez implica un reconocimiento a la importancia de la protección de los valores familiares, pero no entendidos como una carga moralista trivial, sino, por el contrario, interpretados a partir del reconocimiento de la realidad social, en la cual se observa una diversidad de familias, como serían las LGTBI, las monoparentales (solo un padre o una madre), las familias extensas (con tíos, tías, abuelos, abuelas, primos, hermanos mayores) $\mathrm{y}$, en general, todas las relaciones que vinculan un grupo de personas a partir de una comunidad de vida, tal y como la que hoy nos ocupa: la familia de crianza.

Para la Corte Constitucional, el constituyente primario dejó en plano de igualdad la familia que surge de la voluntad responsable de las partes para conformarla y la que tiene origen en el matrimonio. Al respecto, la sentencia C-577 (2011), afirmó:

“Como realidad 'dinámica y vital, donde cobran especial importancia los derechos fundamentales al libre desarrollo de la personalidad, la libertad de conciencia, el derecho a la intimidad', la familia tiene, entonces, 'un régimen constitucional, cuya piedra angular es el artículo 42 , en concordancia con el artículo $5^{\circ}$, régimen que busca hacer de ella 'el ámbito adecuado para que dentro de un clima de respeto, no violencia e igualdad, sus integrantes puedan desarrollarse a plenitud como seres humanos, con la garantía de intimidad que permita el transcurso de la dinámica familiar sin la intromisión de terceros' $\mathrm{y}$, asimismo, lograr un equilibrio entre la estabilidad necesaria para el desarrollo de sus miembros con la dignidad y el libre desarrollo de la personalidad a que tiene derecho cada uno de sus integrantes, aspecto este donde cobra especial importancia la existencia de un ambiente de respeto por cada persona y de libre expresión de los afectos y emociones".

\section{Aspectos constitucionales del concepto de familia-filiación.}

En líneas generales la familia es considerada como uno de los pilares fundamentales del estado social de Derecho (Art. 42 C.P.) En las últimas décadas el concepto de familia se ha modernizado para dejar de ser aquella familia nuclear que vemos en las revistas de farándula, compuesta por un padre, una madre, un niño, una niña y un perro. Es así como, gracias a una serie de grupos ciudadanos, organizaciones no gubernamentales y la jurisprudencia constitucional, se ha establecido una agenda de Estado para el reconocimiento de las formas de familia diversas y darle así un alcance jurídico a una realidad social innegable.

La Corte Constitucional en Sentencia T-705 (2016), explicó que la jurisprudencia constitucional ha reconocido a la familia "como una realidad social de todos los tiempos, que goza de una amplia regulación a nivel interno e internacional, que busca garantizar bienestar y velar por su supervivencia, conservación e integridad. La familia puede ser conformada por vínculos naturales o jurídicos y varía según sea su composición familiar". 
Es importante precisar que es diferente hablar del concepto de Derecho de familia y el de familia como institución, pues creemos que no puede definirse la familia desde un punto de vista estrictamente jurídico, ya que, por la complejidad de las relaciones que ésta implica necesariamente, se debe acudir a las demás ciencias sociales para lograr una definición completa. Es así como es menester acudir a la sociología, al trabajo social, a la historia y hasta a la filosofía para poder entender las diferentes aristas de la familia, mientras que el Derecho de familia se limita solo a determinar las normas jurídicas que regulan las relaciones, obligaciones y efectos personales y patrimoniales de la constitución familiar. Es así como el concepto de familia es dinámico, se encuentra sujeto a la evolución de la sociedad y se ajusta a lo que la sociedad entienda por tal; en este sentido Jiménez Morales (2018) ha explicado que la realidad impone una nueva visión acerca de la familia como institución, partiendo de la tendencia imperante a la diversidad tipológica, coexistente con el arquetipo nuclear en decadencia, aunque aquellos como este tampoco serán eternos, pero, al día histórico-concreto de hoy, pugnan por su justo reconocimiento. Argumentos más que convincentes podrían resultar su factibilidad para los propósitos del desarrollo y la realización personal y social, la necesidad de preservar el principio constitucional supremo de igualdad, y, en general, la defensa de la eficacia constitucional.

La principal fuente de la familia, es sin duda alguna el parentesco, en especial lo que tiene que ver con los temas relativos a la filiación. En términos generales, la filiación es el vínculo jurídico que une a un hijo con su padre o con su madre y que consiste en la relación de parentesco establecida en la ley, entre un ascendiente y un descendiente de primer grado, que encuentra su fundamento en el hecho biológico de la procreación, bien sea que el nacimiento se hubiera producido después del matrimonio o por fuera de este; de allí que se distinga la filiación matrimonial y la extramatrimonial. Y también, encontramos como fundamento legal la filiación adoptiva (Código Civil, art. 250, inc. $2^{\circ}$ ). Conforme a lo dispuesto en el artículo 14 de la Constitución Política, toda persona tiene derecho al reconocimiento de su personalidad jurídica, lo cual es indispensable para que pueda actuar como sujeto de derechos y de obligaciones.

De la existencia, de la igualdad ante la ley y del reconocimiento constitucional a la personalidad jurídica, surgen los atributos de la personalidad y, entre ellos, el del estado civil, el cual determina la situación de una persona en la familia y en la sociedad, y del que se derivan, a su vez, derechos y obligaciones regulados por la ley civil.

El artículo 44 de la Carta señala entre los derechos fundamentales de los niños el tener nombre y nacionalidad, así como tener una familia; y, de la misma manera, el artículo $5^{\circ}$ de la Constitución reconoce sin discriminación la primacía de los derechos inalienable de la persona y ampara a la familia como institución básica de la sociedad. Por su parte, la Convención sobre los Derechos del Niño, adoptada por las Naciones Unidas el 20 de noviembre de 1989 y aprobada por la Ley 12 de 1991, dispuso en el artículo $7^{\circ}$ que el niño será inscrito en el registro civil inmediatamente después de nacido y tendrá derecho, por el sólo hecho del nacimiento, a adquirir un nombre, a conocer a sus padres y a ser cuidado por ellos. Acorde con lo expuesto, la legislación colombiana tiene establecido el derecho de toda persona a saber quiénes son sus progenitores y a establecer su filiación, aún por la 
César Andrés Tirado Pertuz

vía judicial, si fuere necesario. A esta garantía corresponde el deber del Estado de dar todas las oportunidades para asegurar una progenitura responsable, a través del proceso de investigación de la paternidad.

Los derechos relativos a la filiación han sido siempre objeto de debate, de ocultamiento social; un claro ejemplo de ello es la odiosa, y por fortuna superada, distinción que existió hasta hace pocos años en nuestra legislación entre hijos legítimos e hijos naturales; la filiación es sin duda alguna un tema que le interesa mucho a la sociedad conservadora. El debate que nos ocupa en esta oportunidad es sobre los "hijos de crianza", que han tenido un reconocimiento vía jurisprudencial en nuestro país, convirtiéndose de esa forma en un tema inacabado, inexplorado por la doctrina y, en muchos casos, menospreciado.

En verdad, la sociedad entiende que solo a través de los lazos de consanguinidad y/o adopción es posible que alguien pueda llamarse padre o madre de alguien, con todos los derechos y obligaciones que implica esa relación paterno-filial. Hasta ahora, en la mayoría de los casos, los hijos de crianza han contado con una protección que trasciende a lo económico, lo que tiene que ver con el reclamo de alimentos, beneficios corporativos, pensiones sustitutivas o representaciones escolares. En el mejor de los casos, se acepta la situación, pero no el mismo trato, se trata como una especie de tabú el hecho de que en una naciente familia el hombre o la mujer lleguen con hijos/as anteriores y que los incluyan en el núcleo familiar, eso sin dejar de lado los extensos cuestionamientos que se presentan cuando el padre o madre de crianza les da un trato igualitario a los hijos de la pareja. Con frases como "la sangre es más espesa que el agua", se busca descalificar situaciones de este tipo.

\section{Aspectos definitorios de la familia de crianza}

La familia de crianza supone una nueva tipología de filiación o relación paterno - filial, ya que la misma no es de origen biológico y tampoco legal, dada la inexistencia del proceso de adopción.

Desde el punto de vista legal, el art. 67 del Código de Infancia y Adolescencia dispone que "El Estado reconocerá el cumplimiento del deber de solidaridad que ejerce la familia diferente a la de origen, que asume la protección de manera permanente de un niño, niña o adolescente y le ofrece condiciones adecuadas para el desarrollo armónico e integral de sus derechos. En tal caso no se modifica el parentesco". Lo anterior significa que la ley establece que es posible que los lazos que se forman de hecho, sean reconocidos y tengan efectos personales y patrimoniales. Esta es una interpretación amplia del art. 254 del Código Civil que establece que "podrá el juez, en caso de inhabilidad física o moral de ambos padres, confiar el cuidado personal de los hijos a otra persona o personas competentes (...)". Lo dispuesto por este artículo podría ser la semilla de ese reconocimiento de derechos de terceros sobre niños, niñas y adolescentes con los cuales no se tiene un vínculo directo.

La Corte Constitucional en sentencia T-281 (2018) explica que "el legislador reconoce que la figura de familia por lazos de solidaridad puede ocurrir y les da una prelación a las 
personas que tengan a su cuidado a menores de edad sin lazos de consanguinidad, para que al momento de iniciar un proceso de adopción sean tenidos en cuenta de manera preferente". Quiroz Monsalvo (2014) incluye como una forma de familia, aquellas a las que denomina parentales y las define como las familias que se forman por un grupo de personas que no descienden unas de otras y que, sin embargo, constituyen una familia.

\title{
a) Breve Recuento Jurisprudencial
}

La jurisprudencia nacional (Corte Constitucional - Corte Suprema de Justicia) ha sido más o menos uniforme en reconocer los lazos de crianza como una forma de familia y los derechos que ello implica. Es por ello que suele decirse que la categoría "hijo de crianza" es de creación jurisprudencial.

A continuación, conviene hacer una breve recopilación de sentencias que han tratado el tema y que ubican el concepto de hijos de crianza:

Sentencia T-278 (1994): Esta sentencia, si bien no utilizó la categoría "hijo de crianza", se podría considerar como el primer pronunciamiento que se ocupa de la materia, ya que en ella se hace un reconocimiento a "los estrechos vínculos de afecto, solidaridad y respeto entre la menor y los cónyuges”, en ella, la Corte protegió a la menor de manera transitoria y ordenó "instituir a la familia VARGAS BEDOYA como Hogar Amigo de la menor DIANA PATRICIA GUTIERREZ UTIMA, mientras se efectúa el proceso de protección de la niña, en los términos previstos en el artículo 57, numeral $3^{\circ}$ ".

Sentencia T-495 (1997): Esta es la sentencia que habla por primera vez de la categoría "hijos de crianza". En dicha providencia se estudió el caso de Juan Guillermo, quien falleció cuando prestaba el servicio militar, por lo que sus padres de crianza, solicitaron al Ministerio de Defensa Nacional el reconocimiento y pago de una indemnización por la muerte de su hijo. La Corte reconoció el pago de la indemnización por la muerte de su hijo a los accionantes al considerarlos padres de crianza del causante, después de establecer que:

\begin{abstract}
"las pruebas que obran en el expediente dan fe de esa relación filial: 1) la partida de bautismo expedida por la Parroquia de Nuestra Señora de los Dolores de Medellín, según la cual, Juan Guillermo era "hijo de crianza" de Tomás Enrique Vásquez y Carmen Henao; 2) la constancia de la Parroquia de Santa Beatriz de Silva, de la Arquidiócesis de Medellín, según la cual el 22 de noviembre de 1993 fue sepultado el cadáver de Juan Guillermo Vásquez Henao, hijo de Enrique Vásquez y María del Carmen Henao; 3) las declaraciones extrajuicio de Mario de Jesús Zapata Rodríguez y de Marco Fidel Zapata Zapata, según las cuales existió un verdadero vínculo familiar entre los peticionarios y Juan Guillermo, pues el trato entre ellos fue siempre de padres e hijo".
\end{abstract}

Sentencia T-592 (1997): En este caso, la Corte negó el amparo solicitado por cuanto no fue posible establecer que la relación entre la demandante y su hermano, fuera la de una madre y un hijo. En esta sentencia, se dejó claro la necesidad probatoria de la relación de crianza, pues de ello depende la declaración de la misma, concluyéndose que no se trata de una declaración de parte, sino que debe ser sometida al escrutinio juicioso del fallador. 
César Andrés Tirado Pertuz

Sentencia T-292 (2004): Analizó el caso de Susana, una menor que fue entregada por su madre al hogar de Carmen y Roberto, quienes la acogieron como su hija, dándole el apoyo y cariño que necesitaba; la niña los reconocía como sus padres. Después de un año y nueve meses la familia biológica reclamó sus derechos sobre Susana y el ICBF ordenó que la niña fuera ubicada en un hogar sustituto. Carmen y Roberto interpusieron acción de tutela solicitando que la niña regresara con ellos y que se las entregaran en adopción. La tutela fue concedida y protegió el derecho fundamental a tener una familia y a no ser separado de ella, debido a que se demostró que Susana tenía fuertes vínculos de afecto con su familia de crianza y que incluso era a ellos a quienes reconocía como sus padres.

Sentencias T-497 (20059 y T-836 (2014): Estudiaron casos similares al de la T-292 (2004), en los que se cuestionó el actuar del ICBF por haber tomado medidas que vulneraban los derechos fundamentales de los menores al apartar a los niños de sus hogares de crianza, cuando se logró establecer que existían fuertes lazos de amor, respeto, solidaridad y que los menores habían sido acogidos como hijos. También se concluyó que no existía un vínculo fuerte entre los menores y sus padres biológicos.

Sentencia T-606 (2013): Quizás una de las más mediáticas, pues la Corte Constitucional examinó el planteamiento de una persona que adujo que Ecopetrol había vulnerado derechos fundamentales a la familia y a la igualdad, al impedir que se inscribiera a la hija de su compañera permanente como integrante de su familia, a efectos de que le fueran extendidos los beneficios que la convención colectiva estipulaba para los integrantes del núcleo familiar de los trabajadores en materia de salud. En esta oportunidad la Corte amparó los derechos a la igualdad y a la protección integral a la familia, debido a que se logró establecer que la menor llevaba viviendo con el actor más de 7 años, lo que había permitido que ella lo identificara como su padre y que se generaran entre ellos fuertes vínculos de afecto, respeto y protección.

Sentencia T-942 (2014): En esta oportunidad la accionante pidió que se le ordenara a la Caja de Compensación Familiar Comfenalco Santander, que aceptara como beneficiario del subsidio familiar a su nieto de quien tenía la custodia provisional, ya que la madre del menor tenía 23 años y se encontraba estudiando en la universidad. La Corte Constitucional extendió los beneficios derivados del subsidio familiar al nieto y ordenó que el menor fuese considerado por la accionada como hijo de crianza del actor y, correlativamente, debía tener los mismos derechos que sus otros hijos.

Sentencia T-070 (2015): Se analizó el caso en que una empresa que no reconoció un auxilio educativo que estaba contemplado en la convención colectiva de dicha compañía, aduciendo que el menor no era hijo biológico ni adoptivo. En este caso se accedió a la solicitud de tutela, con fundamento en el material probatorio que daba cuenta de la relación existente entre el menor y su padre de crianza. La existencia de dicha relación se basaba en vínculos de afecto, solidaridad, ayuda y comunicación, lo que se demostró con la afiliación, por parte del padre de crianza, del menor como su beneficiario en materia de salud y su inscripción en el colegio. 
Sentencia T-074 (2016): En esta oportunidad la Corte analiza la solicitud de reconocimiento y pago de la pensión de sobrevivientes para un menor, en calidad de hijo de crianza de un nieto a quien el fallecido había criado como suyo, teniendo en cuenta que el padre biológico se encontraba incapacitado. La Corte Constitucional concedió el amparo solicitado aseverando que después de valorar las pruebas, se pudo establecer que el menor era hijo de crianza por asunción solidaria de la paternidad del causante.

Sentencia T- 292 (2016): Se vuelven a analizar las negativas de acceso a beneficios convencionales que fueron otorgados a los hijos biológicos y adoptivos de sus trabajadores, alegando que tienen la condición de hijastros. En ambos casos se hace un estudio acucioso de las pruebas y la Corte tuteló los derechos fundamentales a la igualdad de la familia, fundamentándose principalmente en la siguiente consideración:

“A juicio de la Corte las razones en las que se funda la negativa del Banco de la Republica para impedir el acceso a los beneficios convencionales pretendidos, devienen en discriminatorias, pues no es posible brindar un trato diferente a los hijos de un núcleo familiar en razón de su forma de vinculación al mismo. Bajo esta perspectiva los derechos de los hijos, cualquiera sea su condición, deben prodigarse en condiciones de igualdad. Vistas, así las cosas, resulta inadmisible la posición aludida por la entidad demandada en el sentido de que solo pueden acceder a los beneficios convencionales los hijos biológicos y adoptivos; menos aun cuando se trate de menores de edad, quienes son sujetos de especial protección constitucional".

Adicionalmente, se aseveró que en el caso de que los padres biológicos hayan cumplido con sus obligaciones económicas y afectivas, lo que se pretende garantizar es un máximo de derechos a los menores. Al respectó manifestó que "en virtud del interés superior del menor, se debe propender, no por garantizar un mínimo de derechos a los niños, sino un máximo y de manera progresista".

Sentencia T-325 (2016): En esta sentencia la Corte Constitucional protegió los derechos fundamentales de una menor a la salud y a tener una familia, ordenando la vinculación de la menor al régimen de seguridad social en salud, en calidad de beneficiario de la accionante, quien es madre de crianza.

Sentencia T-316 (2017): En esta sentencia se estudió el caso de una persona a quien Ecopetrol le negó la sustitución pensional, por considerar que la entidad tiene un régimen especial y que la condición parental de nieto del pensionado fallecido no se encontraba incluida dentro de los beneficiarios legales. En esa ocasión, indicó que:

"en Colombia, como consecuencia de la evolución de las relaciones humanas y de la aplicación del principio de solidaridad, existen diferentes tipos de familia. Entonces, el derecho debe ajustarse a las realidades sociales, de manera tal que reconozca y brinde la protección necesaria a las relaciones familiares, donde las personas no están unidas única y exclusivamente por vínculos jurídicos o biológicos, sino en virtud de los lazos de afecto, solidaridad, respeto, protección y asistencia". 
César Andrés Tirado Pertuz

Sentencia T- 281 (2018): En esta sentencia se fijan los aspectos procesales que deben tenerse en cuenta para el reconocimiento constitucional de la familia de crianza y se hace el reconocimiento de una pensión sustitutiva a un hijo de crianza, discapacitado. Por otra parte, la Corte Constitucional en sentencia C-107 (2017) declaró exequibles los artículos $4^{\circ}$ y $5^{\circ}$ de la Ley 70 de 1931 que autoriza la constitución de patrimonios de familia no embargables, pero en el entendido de que el patrimonio de familia podrá constituirse a favor de los integrantes de la familia unipersonal y de crianza, y a los integrantes de la familia extensa.

Atendiendo al amplio antecedente jurisprudencial, se demandó el art. 13 de la Ley 797 de 2003, buscando incluir a los parientes de crianza como beneficiarios de esta; sin embargo, en sentencia C-134 de 2018, la Corte Constitucional se declaró inhibida por ineptitud sustantiva de la demanda.

La Sala de Casación Laboral de la Corte Suprema de Justicia, en Sentencia de Casación $N^{\circ}$ 9125, del 13 de diciembre de 1996, realizó analogía entre la posesión notoria de hijo contemplada en el código civil y los "hijos de crianza", para determinar la posibilidad de solicitar la pensión sustitutiva. Esta postura ha sido reiterada en varias providencias.

La Sala Penal de la Corte Suprema de Justicia, también se refirió a la familia de crianza, en un caso de fraude procesal por presunta presentación de un registro civil de nacimiento al interior de un proceso de unión marital de hecho y sucesión intestada de un hijo que no es hijo biológico. En sentencia SP2299 (2019) encontró justificada y absolvió a la imputada del delito de fraude procesal, sobre el entendido de que prevalecía la protección del derecho fundamental a la filiación, cuyo ámbito de protección está delineado por la definición tanto del estado civil como de los atributos de la personalidad del individuo, en relación con los cuales han de ceder intereses de terceros, principalmente patrimoniales, y desarrolla la familia de crianza como una expresión de esa situación, lo que abre la puerta a la protección de la familia de crianza entre los órdenes sucesorales.

Por su parte, la Sala Civil de la Corte Suprema de Justicia en STC14680 (2015) señaló que:

"El grupo familiar está compuesto no solo por padres, hijos, hermanos, abuelos y parientes cercanos, sino que incluye también a personas entre quienes no existen lazos de consanguinidad, pero puede haber relaciones de apoyo y afecto incluso más fuertes, de ahí que no haya una única clase de familia, ni menos una forma exclusiva para constituirla".

Y, posteriormente, en sentencia STC6009 (2018) estableció la posibilidad del reconocimiento judicial, a través de un proceso de jurisdicción voluntaria la existencia de un vínculo de crianza. Esto a partir del reconocimiento que, por vía jurisprudencial se había efectuado a las familias de crianza.

Sobre este caso concreto, la Corte concluyó que el operador judicial incurrió en un defecto sustantivo, pues sin detenerse a verificar si la demanda reunía los requisitos formales del 
Código General del Proceso, se apresuró a rechazarlo, bajo un argumento que no constituye una causal enunciada en la norma. Si bien encontró que el juez erró en su decisión, resaltó que con ello no se indicaba que la pretensión de la demandante debía ser acogida por el juzgador al momento de dictar sentencia, sino que se pretendía poner de presente "la existencia de múltiples decisiones judiciales que evidencian una situación sensible en el devenir humano, que por lo menos amerita dar curso a la demanda, con independencia de la resolución final que se adopte" (Sentencia STC 6009, 2018); postura reiterada en sentencia STC238 (2019).

Finalmente, el Consejo de Estado ha tenido diversos pronunciamientos al respecto, como en su sección tercera en las sentencias 18846 (2008), 18073 (2009), 20733 (2011), 31252 (2013) y 27289 (2013), o en la sección cuarta en las sentencias AC-2008-00244 (2008) y 05001-23-31-000-2009-00197-01 AC (2009); en los que se admite el vínculo de crianza como forma válida de familia, reconociéndole a cualquiera de sus integrantes legitimidad para reclamar el resarcimiento de perjuicios por daños antijurídicos imputables al Estado, haciendo una interpretación amplia del concepto de adopción. Sirva de ejemplo la sentencia 18846 del 16 de marzo de 2008 proferida por la Sección Tercera del Consejo de Estado.

\section{b) El Proyecto de Ley 160 (2019)}

Todo lo anterior caracteriza el establecimiento de la familia de crianza, la cual ha sido introducida de forma sistemática por la jurisprudencia, creando la necesidad de legislar al respecto, pues es claro que hace falta un reconocimiento legal de esta situación de hecho en las familias colombianas. En este escenario, el senador colombiano José Ritter López (2019), radicó ante la Secretaría General del Senado, el proyecto de Ley 160 (2019), publicado en la Gaceta del Congreso de la República el 9 de septiembre (2019), por el cual se dictan disposiciones sobre las familias de crianza en el país. Según el mencionado senador, con este proyecto se busca establecer un marco legal y soporte jurídico que reconozca los derechos de estas personas que tienen una unión de hecho, es decir, que no están amparados por un marco legal ni de consanguinidad.

En el proyecto se incluye: 1. Definición de familia de crianza. 2. Un procedimiento ante un juez de familia para que se realice el reconocimiento del vínculo. 3. Una relación de los medios probatorios necesarios para determinar la existencia del vínculo pretendido. 4 . Se otorgan derechos sucesorales a los parientes de crianza. 5. Se permiten las visitas de los parientes de crianza a las personas privadas de la libertad.

El proyecto de ley recoge en gran parte los aspectos fundamentales de las familias de crianza, ya que precisa una definición legal de "hijo de crianza" a partir de la interpretación usada de manera sistemática por la jurisprudencia. Sin embargo, es claro que de la lectura de la ley resulta pertinente, además, aclarar aspectos como:

- ¿Qué relación tendría la familia biológica del hijo de crianza?

- ¿Qué sucedería si se separa la familia?

- ¿Los hijos de crianza se incluyen en el primer orden hereditario? 
César Andrés Tirado Pertuz

- ¿Los hijos de crianza estarían en las mismas inhabilidades, incompatibilidades civiles o administrativas (nulidades matrimoniales o contratación pública), o delitos relacionados con la familia biológica o adoptiva?

Además de los anteriores interrogantes, lo cierto es que el reconocimiento legal de esta situación es necesario en el país, pero para ello se deben tener en cuenta los aspectos fundamentales fijados por la jurisprudencia ya analizada.

Actualmente, según la jurisprudencia de la Sala Civil de la Corte Suprema de Justicia, se puede hacer el reconocimiento de la condición de hijo de crianza a través de un proceso declarativo ante el juez de familia, o hacerla valer a través de los medios probatorios que acrediten la condición de tal, al interior de un determinado proceso, sea administrativo, laboral, civil, e incluso penal como se pudo apreciar en la sentencia SP2299 (2019). En todo caso, la protección de los derechos que entrañan dicho reconocimiento también se puede obtener por vía de tutela. Sea cual sea el camino procesal que se escoja, lo cierto es que sí resulta pertinente tener en cuenta algunos aspectos sustanciales y otros procesales, que revisten vital importancia al momento de determinar la existencia de tal vínculo.

\section{c) Aspectos Sustanciales}

La familia de crianza es en esencia una situación de hecho que requiere reconocimiento por parte de una autoridad judicial o administrativa. Para ello es necesario tener en cuenta que dicho vínculo está compuesto por una serie de elementos que lo caracterizan y permiten determinar la existencia de la relación paterno-filial que se alega. Tomando los elementos de las sentencias citadas en precedencia, destacamos como tales los siguientes:

- La solidaridad: Como lo expresa el art. 67 del Código de Infancia y Adolescencia, debe de existir una relación de solidaridad entre el hijo y los padres de crianza. Para poder determinar este elemento se requiere un análisis de la situación familiar, en particular la causa que motivó al padre o madre de crianza a generar una cercanía con el hijo.

Reemplazo de la figura paterna o materna (o ambas): Al decir de la Corte Constitucional en sentencia T-281 (2018), corresponde demostrar:

"si el padre de crianza tiene parentesco con el hijo, pero no será determinante en la evaluación de la existencia de la familia de crianza, ya que en la búsqueda de la prevalencia del derecho sustancial se privilegiará la crianza misma así provenga de un familiar".

La dependencia económica: Este es un aspecto fundamental cuando lo que se está solicitando es de carácter patrimonial y permite también determinar la separación del hijo de crianza de su familia biológica, quienes serían los primeros obligados a erogar los gastos de crianza y educación del hijo (Art. 257 del C.C.).

Vínculos de afecto, respeto, comprensión y protección: Hacen alusión a aspectos íntimos de la familia y se concretan en el apego del hijo de crianza, en la afectación 
moral y/o emocional que llegan a sufrir los miembros de la familia de crianza en caso de ser separados.

Reconocimiento de la relación padre y/o madre, e hijo: Hace alusión a la necesidad de que la relación familiar sea pública, que socialmente o al menos por parte de los integrantes de la familia, sea conocida la relación paterno-filial existente. En palabras de la Corte Constitucional "debe ser observada con facilidad por los agentes externos al hogar" (T-281, 2018).

\section{Existencia de un término razonable de relación afectiva entre padres e hijos.} Aunque no existe un término definido, y tampoco el proyecto de ley antes comentado lo contempla, lo cierto es que las reglas de experiencia enseñan que es necesario que transcurra un lapso importante (2, 3 años o más) que forje los vínculos afectivos entre padres e hijos. Por analogía, con la presunción establecida para la existencia de la Sociedad Patrimonial que se forma en la Unión Marital de Hecho, podría fijarse un término mínimo de 2 años (Art. $2^{\circ}$ ley 54 de 1990), sin embargo, esto no es óbice para que se concrete la relación antes de ese término.

Afectación del principio de igualdad: Es sin duda uno de los temas más controversiales que se plantean al analizar la familia de crianza. Se requiere que se demuestre que el trato que le da el padre al hijo de crianza es idéntico al que le da al hijo biológico, situación bien difícil de probar en nuestra sociedad. Parra Benítez (2019) analiza la distinción entre la familia biológica y la de crianza, llegando a la conclusión de que la primera goza de una presunción a su favor. La Corte Constitucional por su parte señala en Sentencia T-281 (2018), sobre este aspecto que:

"Se configura en idénticas consecuencias legales para las familias de crianza, como para las biológicas y jurídicas, en cuanto a obligaciones y derechos y, por tanto, el correlativo surgimiento de la protección constitucional. En la medida en que los padres de crianza muestren a través de sus actos un comportamiento tendiente a cumplir con sus obligaciones y deberes en procura de la protección y buen desarrollo de los hijos, se tendrá claro que actúan en condiciones similares a las demás familias, por lo que serán beneficiarias de iguales derechos y prestaciones".

\section{d) Aspectos Procesales}

Como se ha recalcado el reconocimiento de la familia de crianza, en el escenario que se escoja, es eminentemente probatorio, tal como lo señala la Corte Constitucional en la sentencia T-592 (1997). Es así como las decisiones se encuentran sujetas a los problemas probatorios usuales en los casos de familia, que son de difícil probanza debido a la intimidad y moralidad de las relaciones que se pretende probar. Los vínculos de crianza están, pues, sujetos a la forma como se le presenten al juez, tal como lo afirma Luna Salas (2019, p. 56) “(...) la búsqueda de la verdad en el proceso judicial es un objetivo difícil de satisfacer en modo pleno, por lo cual se plantea que frente al proceso lo que se tiene es una verdad con carácter de validez. Así, para el proceso los hechos son conforme se han probado y no como ocurrieron en realidad". 
César Andrés Tirado Pertuz

En particular, el proyecto de ley número 160 de 2019 (Senado de la República, 2019) trae algunos aspectos procesales que vale la pena analizar:

“Artículo $3^{\circ}$. Procedimiento. La declaración del reconocimiento como hijo de crianza se tramitará ante el juez de familia del domicilio del que pretende reconocerse como hijo de crianza, por el procedimiento de jurisdicción voluntaria establecido en el Libro III, Sección IV del Código General del Proceso. Parágrafo. En la sentencia de declaración de reconocimiento de hijo de crianza, el juez, subsidiariamente, resolverá que los declarantes o demandantes serán padre y/o madre de crianza".

La anterior norma regula lo explicado por la Corte Suprema de Justicia, estableciendo la competencia en cabeza del juez de familia, y señalando que se hará a través de un proceso de jurisdicción voluntaria; a diferencia de lo que sucede actualmente, pues el reconocimiento del vínculo se busca a través de un proceso declarativo. Sin embargo, la norma no deja claro qué ocurre con la patria potestad, situación que debe ser dilucidada y no dejarla al arbitrio de la jurisprudencia. Aunque en el art. $4^{\circ}$ que se analiza más adelante, sí se establece que la relación con el padre biológico debe ser precaria o nula, lo cierto es que dicha situación no es suficiente, sobre todo en lo relativo a la representación que es uno de los derechos principales que viene con la patria potestad. Es una oportunidad para zanjar esa inquietud, pese a que, para la Corte Constitucional, es viable la subsistencia de los dos vínculos según la sentencia T - 292 (2016).

Por su parte, el artículo $4^{\circ}$ del proyecto de ley establece, a título enunciativo, una serie de medios probatorios que se deben tener en cuenta para la prosperidad de la pretensión en el proceso judicial. Textualmente señala:

"La declaración del reconocimiento como hijo de crianza se establecerá por los medios ordinarios de prueba, consagrados en el artículo 165 del Código General del Proceso y en particular, los siguientes:

a) Evidencia de una relación inexistente o precaria con sus padres biológicos o de la muerte de estos, y demostración de acogida de los menores como si fueran sus hijos a través de fuertes lazos de solidaridad, afecto y respeto, y el sostenimiento de sus necesidades.

b) Declaraciones de los menores y de otros familiares o personas cercanas.

c) El otorgamiento de la custodia de manera provisional.

d) Conceptos psicológicos.

e) Partida de bautismo en donde se indica que los padres son de crianza.

f) Informes del ICBF a partir de visitas de campo.

g) Afectación del principio de igualdad.

h) Existencia de un término razonable en relación afectiva entre padres e hijos.

i) Las demás que considere pertinentes y conducentes en cada caso.

La carga de la prueba se establecerá en los términos del artículo 167 del Código General del proceso". 
Especial atención llama el ordinal a) según el cual lo primero a probar en el proceso es la inexistente o precaria relación del menor con sus padres biológicos. Lo cual, como ya se indicó, supone un conflicto entre la relación de "crianza" y los derechos de la patria potestad, que según el art. 288 del Código Civil colombiano, se encuentra reservada exclusivamente a los padres biológicos o adoptivos. En la exposición de motivos de la ley, el ponente destaca al respecto:

“(...) la familia de crianza que reclame la declaración del reconocimiento como hijo de crianza al menor con el cual ha creado el vínculo de hecho, puede estar legitimada para pretender la privación de la patria potestad de los padres biológicos del menor, sin que su intención sea la de modificar el parentesco del menor con relación a sus padres biológicos, aunque, como se dijo anteriormente, esta suspensión o privación se inscriba en el registro civil de nacimiento.

Es oportuno recordar en este punto, que el vínculo que une a la familia de crianza es un vínculo de hecho, y que, tal como la sociedad comercial de hecho y la unión marital de hecho, sus efectos son diferentes a los vínculos jurídicos de los demás tipos de familia (no modifica el parentesco). Los reconocimientos que se conceden son en virtud de los principios de pluralismo, de solidaridad, de dignidad humana, y de los derechos a la igualdad, a no ser discriminado por el origen familiar y a tener una familia y no ser expulsado de ella.

Bajo estos preceptos, la pretensión de la familia de crianza es, en observancia del principio de solidaridad y los demás ampliamente mencionados en esta exposición de motivos, brindar amor, protección, seguridad y los demás derechos de los niños contemplados en el artículo 44 de la Constitución Nacional a los menores que han acogido en su seno, no modificar su parentesco (en concordancia con lo estipulado en el artículo 67 del Código de la Infancia y la Adolescencia); por lo cual, la patria potestad continúa en cabeza de sus padres biológicos, o solo las obligaciones derivadas de esta, en caso de haber sido objeto de suspensión o privación de la misma."

Conforme a lo anterior, es claro que la intención del legislador es que se mantenga la relación biológica y la de crianza, prevaleciendo la primera en todo caso. Nos parece más adecuado interpretar que el reconocimiento del vínculo de crianza establecido en el Par. del Art. $3^{\circ}$ del proyecto de ley, supone una terminación de la patria potestad respecto a los padres biológicos y/o adoptivos, para que la misma sea asumida por el padre o madre de crianza, fijando de esta manera, una certeza respecto a la familia del menor y evitando los litigios futuros que frente a ello se puedan presentar, en casos tan sencillos como, por ejemplo, una solicitud de salida del país del menor con el padre o madre de crianza, o la representación ante una institución educativa.

Otro aspecto que de discusión es si el reconocimiento de la familia de crianza, es una especie de "Adopción de Hecho", sobre lo cual, habría que responder que sí. Al respecto, el proyecto de ley 160 (2019) intenta zanjar este planteamiento incluyendo en las motivaciones una distinción entre el hijo adoptivo y el hijo de crianza, señalando que mientras 
“(...) el hijo adoptivo tiene un vínculo jurídico con su adoptante. El hijo de crianza ostenta un vínculo de hecho. (...). La adopción, al ser un vínculo jurídico, modifica el estado civil del adoptivo. El hijo de crianza, al tener un vínculo de hecho, no modifica el estado civil del hijo. La adopción modifica la filiación por vía jurídica. El hijo de crianza modifica la filiación ante la sociedad. (...) El hijo adoptivo rompe el parentesco con su familia biológica. El hijo de crianza, al no modificar su estado civil, lo mantiene. Al hijo adoptivo se le otorgan derechos y obligaciones como a un hijo consanguíneo en virtud de su nuevo vínculo jurídico. En el caso del hijo de crianza, estos derechos y obligaciones se le conceden a la luz de la principialística".

Por otra parte, el literal f) implica la necesidad de vincular al ICBF al proceso de reconocimiento, y que el mismo rinda un informe técnico al interior del proceso. Los demás literales son claramente ejemplos de medios probatorios que se pueden usar, y deja finalmente la carga de la prueba a las reglas generales del Código General del Proceso.

\section{CONCLUSIONES}

La existencia de los hijos de crianza es una realidad innegable que debe ser reconocida por el legislador. Es común hoy en día conocer casos en donde los menores no tienen relación con sus padres biológicos, y en cambio han reemplazado esa figura con un tercero que los acogió como si fueran sus hijos, derivándose entre los hijos y los miembros de la familia de crianza relaciones con fuertes lazos de solidaridad, afecto y respeto, además de asumir la totalidad de los gastos de los menores.

En todo caso, tal como se observa en las sentencias T-278 (1994), T-495 (1997), T-497 (2005), T-292 (2016) y T-325 (2016) de la Corte Constitucional, de la Corte Suprema de Justicia y del Consejo de Estado, es imprescindible la presencia de material probatorio suficiente que dé cuenta de la existencia de los elementos que definen la categoría "hijos de crianza". Por ello, el proyecto de ley que reposa actualmente en el Senado colombiano incluye una lista que, aunque no es taxativa, si da cuenta de los lineamientos recogidos por la jurisprudencia.

Entre el material relevante para estos efectos se han considerado, por ejemplo, declaraciones de los menores y de otros familiares o personas cercanas, el otorgamiento de la custodia de manera provisional, conceptos psicológicos, partida de bautismo en la que se indica que los padres son de crianza, informes del ICBF, entre otros. Ante la ausencia o insuficiencia de material probatorio no es posible establecer la relación que le solicitan al juez que declare y, en esa medida, no cabe otra alternativa que negar el reconocimiento de la pretensión, tal como fue el caso de la sentencia T-592 (1997).

Lo cierto es que la Corte Constitucional le da prevalencia a la familia de crianza, incluso por encima de la biológica, siempre y cuando se demuestre que hay una ruptura de los vínculos afectivos entre esta última y el menor, y que un cambio familiar va en contra del interés superior de éste (Sentencia T-292, 2004). Del mismo modo, también ha sido prevista la coexistencia de las dos formas de vínculo familiar (Sentencias T-606, 2013; T-070, 2015 y T- 292, 2016). 
La mayoría de los casos revisados por la jurisprudencia obedecen a una necesidad patrimonial de reconocimiento de los hijos de crianza, para poder acceder a los beneficios contemplados en convenciones colectivas o empresariales, pensiones o indemnizaciones.

Por otro lado, en algunos casos el reconocimiento de la familia de crianza supone una tensión entre los derechos de los padres biológicos y los de "crianza", fundamentalmente los relacionados con el ejercicio de la patria potestad. Además, si se llegare a entender como una "adopción de hecho", es muy probable que algunas familias a las que les cuesta iniciar un proceso de adopción por cualquier razón, terminen acudiendo a esta figura, la cual, sin duda alguna, se extiende a todo tipo de familias, bien sea multifiliales, monoparentales o las compuestas por parejas del mismo sexo.

\section{REFERENCIAS BIBLIOGRÁFICAS}

Código Civil. Ley 57 de 1887. Abril 15 de 1887. (Colombia).

Código General del Proceso. Ley 1564 de 2012. Julio 12 de 2012. (Colombia).

Código de Infancia y Adolescencia. Ley 1098 de 2006. Noviembre 8 de 2006 (Colombia).

Congreso de la República de Colombia. Ley 70 de 1931. Que autoriza la constitución de patrimonios de familia no embargables. Mayo 28 de 1931.

Congreso de la República de Colombia. Ley 75 de 1968. Por la cual se dictan normas sobre filiación y se crea el Instituto Colombiano de Bienestar Familiar. Diciembre 30 de 1968.

Congreso de la República de Colombia. Ley 12 de 1991. Por la cual se aprueba la Convención sobre los Derechos del Niño adoptada por la Asamblea General de las Naciones Unidas, el 20 de noviembre de 1989. Enero 22 de 1991.

Congreso de la República de Colombia. Ley 797 de 2003. Por la cual se reforman algunas disposiciones del sistema general de pensiones previsto en la Ley 100 de 1993 y se adoptan disposiciones sobre los Regímenes Pensionales exceptuados y especiales. Enero 29 de 2003.

Constitución Política de Colombia. Arts. 5, 14, 42 y 44. Julio 7 de 1991 (Colombia).

Corte Constitucional. Sala sexta de revisión. Sentencia T-278 de 1994. [M.P Hernando Herrera Vergara; junio 15 de 1994]

Corte Constitucional. Sala cuarta de revisión de tutelas. Sentencia T-495 de 1997. [M.P Carlos Gaviria Díaz; octubre 3 de 1997]

Corte Constitucional. Sala primera de revisión. Sentencia T-592 de 1997. [M.P Jorge Arango Mejía; noviembre 18 de 1997] 
César Andrés Tirado Pertuz

Corte Constitucional. Sala tercera de revisión, Sentencia T-292 de 2004. [M.P Manuel José Cepeda Espinosa; marzo 25 de 2004]

Corte Constitucional. Sala quinta de revisión. Sentencia T-497 de 2005. [M.P Rodrigo Escobar Gil; mayo 13 de 2005]

Corte Constitucional. Sala octava de revisión. Sentencia T-606 de 2013. [M.P Alberto Rojas Ríos; septiembre 2 de 2013]

Corte Constitucional. Sala primera de revisión. Sentencia T-836 de 2014. [M.P María Victoria Calle Correa; noviembre 11 de 2014]

Corte Constitucional. Sala tercera de revisión. Sentencia T-942 de 2014. [M.P Luis Guillermo Guerrero Pérez; diciembre 3 de 2014]

Corte Constitucional. Sala octava de revisión. Sentencia T-070 de 2015. [M.P Martha Victoria Sáchica Méndez; febrero 18 de 2015]

Corte Constitucional. Sala octava de revisión. Sentencia T-074 de 2016. [M.P Alberto Rojas Ríos; febrero 22 de 2016]

Corte Constitucional. Sala cuarta de revisión. Sentencia T- 292 de 2016. [M.P Gabriel Eduardo Mendoza Martelo; junio 2 de 2016]

Corte Constitucional. Sala quinta de revisión. Sentencia T-325 de 2016. [M.P Gloria Stella Ortiz Delgado; junio 22 de 2016]

Corte Constitucional. Sala cuarta de revisión. Sentencia T-316 de 2017. [M.P Antonio José Lizarazo Ocampo; mayo 12 de 2017]

Corte Constitucional. Sala octava de revisión. Sentencia T- 281 de 2018. [M.P José Fernando Reyes Cuartas; julio 23 de 2018]

Corte Constitucional. Sala plena. Sentencia C-107 del 2017. [M.P Luis Ernesto Vargas Silva; febrero 22 de 2017]

Corte Constitucional. Sala plena. Sentencia C-134 del 2018. [M.P Antonio José Lizarazo Ocampo; noviembre 28 de 2018]

Corte Suprema de Justicia. Sala Penal. Sentencia SP2299 del 2019. [M.P Patricia Salazar Cuellar; mayo 14 de 2019]

Corte Suprema de Justicia. Sala Civil. Sentencia STC14680 del 2015. [M.P Ariel Salazar Ramírez; octubre 23 de 2015] 
Corte Suprema de Justicia. Sala Civil. Sentencia STC6009 del 2018. [M.P Aroldo Wilson Quiroz Monsalvo; mayo 9 de 2018]

Corte Suprema de Justicia. Sala Civil. Sentencia STC238 del 2019. [M.P Álvaro Fernando García Restrepo; enero 21 de 2019]

Corte Suprema de Justicia. Sala de Casación Laboral. Sentencia 9125 de 1996. (M.P. Francisco Escobar Henríquez; diciembre 13 de 1996).

Consejo de Estado. Sección tercera. Sentencia No. 18846 del 2008. [M.P. Enrique Gil Botero; marzo 26 de 2008]

Consejo de Estado. Sección tercera. Sentencia No. 18073 del 2009. [M.P Enrique Gil Botero; enero 28 de 2009]

Consejo de Estado. Sección tercera. Sentencia No. 20733 del 2011. [M.P Hernán Andrade Rincón; abril 7 de 2011]

Consejo de Estado. Sección Tercera. Sentencia No. 31252 del 2013 [M.P Enrique Gil Botero; julio 11 de 2013]

Consejo de Estado. Sección tercera. Sentencia No. 27289 del 2013. [M.P Enrique Gil Botero; julio 24 de 2013].

Consejo de Estado. Sección cuarta. Sentencia No. AC- 2008-00244 del 2008 [M.P Ligia López Díaz; septiembre 25 de 2008]

Consejo de Estado. Sección cuarta. Sentencia No. 05001-23-31-000-2009-00197-01(AC) del 2009. [M.P Martha Teresa Briceño; mayo 6 de 2009].

Jiménez Morales, C. R. (2018). La Familia: Redimensionamiento del contenido esencial de su concepto. Bogotá, Colombia: Editorial Temis.

Kalach Torres, Gina María. Las comisiones de la verdad en Colombia. En Revista Jurídica Mario Alario D'Filippo, vol. 8, núm. 16: p. 106-124, 2016. Recuperado de: https://doi.org/10.32997/2256-2796-vol.8-num.16-2016-1534

Luna Salas, F. (2019). Hechos, Verdad y Prueba. En F. Luna y E. de Río. Compendio de Derecho Probatorio Contemporáneo, p. 39-59. Bogotá, Colombia: Grupo Editorial Ibáñez.

Luna Salas, F. (2019). Técnicas neurocientíficas como medio de prueba pericial. Revista Prolegómenos. Vol. 22, Número 44: 143-154 DOI: https://doi.org/10.18359/prole.4160 
César Andrés Tirado Pertuz

Monroy Cabra, M. G. (2001). Derecho de Familia y de Menores. Bogotá, Colombia: Editorial Ediciones Librería del Profesional.

Parra Benítez, J. (2019). Derecho de Familia Tomo I Parte Sustancial. Bogotá, Colombia: Editorial Temis.

Quiroz Monsalvo, A. (2014). Manual Civil. Tomo V. Bogotá, Colombia: Ediciones Doctrina y Ley Ltda.

Ritter López, José. (2019). En Boletín de Prensa del Senado de la República de Colombia, del 27 de agosto de 2019. Recuperado de: http://www.senado.gov.co/index.php/component/content/article/18-noticiasactualidad/178-hijos-de-crianza-tendrian-los-mismos-derechos-de-los-hijos-naturalesy-adoptivos

Senado de la República de Colombia. Proyecto de ley núm. 160 de 2019. Por medio del cual se dictan disposiciones sobre la familia de crianza. G.O. $\mathrm{N}^{\circ} 832$ del 9 de septiembre de $2019 . \quad$ Recuperado de: http://www.secretariasenado.gov.co/legibus/legibus/gacetas/2019/GC 0832 2019.pdf

Suarez Franco, R. (2006). Derecho de Familia: Tomo II. Bogotá: Editorial Temis.

Tirado, C. y Luna, F. (2015). La creación pretoriana del Derecho Procesal Constitucional en la Acción de Tutela. Revista Jurídica Mario Alario D’Filippo, Vol. 7, número 14: 2240. DOI: https://doi.org/10.32997/2256-2796-vol.7-num.14-2015-1515

Valencia Zea, A. y Ortiz Monsalve, Á. (1994). Derecho Civil, Tomo I: Parte General y Personas. Bogotá, Colombia: Editorial Temis.

Viguri Perea, A. y Chiara Marullo, M. El derecho a un medio ambiente sano y la encrucijada de los alimentos transgénicos. En Revista Jurídica Mario Alario D'Filippo, vol. 8, núm 15: p. 100-111, 2016. Recuperado de: https://doi.org/10.32997/2256-2796vol.8-num.15-2016-1526

\section{ANEXO:}

\section{PROYECTO DE LEY NÚMERO 160 DE 2019 SENADO}

"por medio de la cual se dictan disposiciones sobre la familia de crianza" El Congreso de Colombia DECRETA:

Artículo $1^{\circ}$. Objeto. El objeto de esta ley es definir la figura de la familia de crianza, establecer su naturaleza, determinar sus medios probatorios y reconocer derechos y obligaciones entre sus miembros. 
Artículo $2^{\circ}$. Definiciones. Para todos los efectos prestacionales y asistenciales, se define y se reconoce como familia de crianza a aquella en la cual han surgido de hecho, y por causa de la convivencia continua, estrechos lazos de amor, afecto, apoyo, solidaridad, respeto, auxilio y ayuda mutuos entre sus integrantes, propios de la relación paterna y/o materna con sus hijos legítimos, extramatrimoniales y adoptivos. Se denominan padre y/o madre de crianza e hijo de crianza a quienes conforman la familia de crianza, sin perjuicio de que entre estos existan vínculos consanguíneos o jurídicos.

Artículo $3^{\circ}$. Procedimiento. La declaración del reconocimiento como hijo de crianza se tramitará ante juez de familia del domicilio del que pretende reconocerse como hijo de crianza, por el procedimiento de Jurisdicción Voluntaria establecido en el libro III, sección IV del Código General del Proceso. Parágrafo. En la sentencia de declaración de reconocimiento de hijo de crianza, el juez, subsidiariamente, resolverá que los declarantes o demandantes serán padre y/o madre de crianza.

Artículo $4^{\circ}$. Medios Probatorios. La declaración del reconocimiento como hijo de crianza se establecerá por los medios ordinarios de prueba, consagrados en el artículo 165 del Código General del Proceso y en particular, los siguientes: a) Evidencia de una relación inexistente o precaria con sus padres biológicos o de la muerte de estos, y demostración de acogida de los menores como si fueran sus hijos a través de fuertes lazos de solidaridad, afecto y respeto, y el sostenimiento de sus necesidades. b) Declaraciones de los menores y de otros familiares o personas cercanas. c) El otorgamiento de la custodia de manera provisional. d) Conceptos psicológicos. e) Partida de bautismo en donde se indica que los padres son de crianza. f) Informes del ICBF a partir de visitas de campo. g) Afectación del principio de igualdad. h) Existencia de un término razonable en relación afectiva entre padres e hijos. i) Las demás que considere pertinentes y conducentes en cada caso. La carga de la prueba se establecerá en los términos del artículo 167 del Código General del proceso.

Artículo $5^{\circ}$. Hijos de crianza en las sucesiones. Los hijos de crianza, frente a su familia de crianza podrán tener, en materia de sucesión testada y en virtud de la voluntad del causante, la calidad de herederos o legatarios. Cuando se trate de sucesión intestada o abintestato el juez, en cada caso, aplicará la ponderación de principios con el fin de determinar la calidad de heredero del hijo de crianza.

Artículo $6^{\circ}$. Hijos de crianza y personas privadas de la libertad. El Gobierno nacional, a través del Ministerio de Justicia, procederá a expedir la reglamentación en la que se incluya las visitas a las personas privadas de la libertad, de los hijos de crianza del interno, definiendo también las condiciones en que deben llevarse a cabo tales visitas.

Artículo $7^{\circ}$. Vigencia. La entrada en vigencia de esta ley se dará a partir de su publicación.

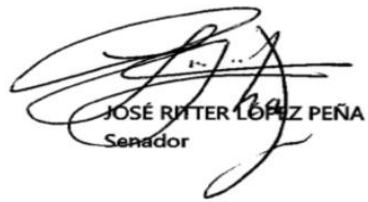

